\title{
Illegal Plant Genetic Resource Trafficking in the Border Villages of Kafta Humera Wereda, Tigray Regional State, Ethiopia
}

\author{
Fitsumbirhan Tewelde \\ Ethiopian Biodiversity Institute, Mekelle Center, Forest and Range Land Biodiversity Case Team, Mekelle, Ethiopia
}

Email address:

fitsumbrhantewelde@yahoo.com

\section{To cite this article:}

Fitsumbirhan Tewelde. Illegal Plant Genetic Resource Trafficking in the Border Villages of Kafta Humera Wereda, Tigray Regional State, Ethiopia. Agriculture, Forestry and Fisheries. Vol. 6, No. 4, 2017, pp. 130-137. doi: 10.11648/j.aff.20170604.14

Received: May 3, 2017; Accepted: May 24, 2017; Published: July 31, 2017

\begin{abstract}
A survey to identify illegal plant genetic resource trafficking was made from February 2017 to March 2017 in Kafta Humera wereda, Tigray regional state, northern Ethiopia. Semi- structured interviews, structured questionnaires; focus group discussion and document analysis were used for data collection. A total of seventy one informants from local security, local community federal policies and custom and revenue officers were interviewed. Snowball sampling was used to select the local community and local security while the rest informant was purposely selected. Microsoft excel spreadsheet and Spss version 20 was used to analyze data. The Leave of Rhamnus prinoides together with its fruits, and fruits of Adansonia didgitata are the frequently exported plant and plant derivatives through illegal route. These plant biogenetic resources are exported to Sudan and Eritrea both by illegally and legally coverage. The awareness of the informants participated in the interview on illegal biogenetic resource trafficking varies from site to site and from sector to sector. The main illegal route whereby illegal traffickers use to export plant and plant derivative are Maytselot, Menkerker, Awezruf, endaaboy Tewelde garden and Haji Abdugarden. Most of the traffickers are unemployed youth that live in and around the border. The existing gap in community awareness needs awareness raising and alternative job opportunities creations. The link between different stakeholders also needs solidarity to accomplish consistent controlling mechanism.
\end{abstract}

Keywords: Illegal Route, Trafficker, Biogenetic, Kafta Humera, Rhamnus prinoides

\section{Introduction}

Forest genetic resources/ FGR/ offer major opportunities for people to cope with important challenges such as climate change and the increasing demand for food, energy, wood products and environmental services [1]. To achieve their value fully, countries and their citizens require political dedication, effective institutions and relevant policies and legislation in order to respond to imperative and increasingly varied needs in conservation and FGR management [2].

The Convention on International Trade in Endangered Species of Wild Fauna and Flora (CITES) saves from harm many species of animals and plants to guarantee that legal and illegal commercial demand does not threaten their endurance in the wild. Ethiopia is a country that signed an international convention on biological diversity [3]. More ever, Ethiopia has taken a number of basic measures on biodiversity conservation and promotion of sustainable utilization, including putting in place domestic legislations and promotion the former Plant Genetic Resources Centre to Ethiopian Biodiversity Institute so that it can deal with plant and other bio genetic resources [2]. Awareness building at all levels is a key prerequisite for mobilizing popular support and international cooperation to advance the conservation and reducing illegal trafficking status of forest genetic resource and their derivatives [1].

The most important threats to forest genetic resource are Forest change and expansion of crop land, Demand for energy, flawed harvesting and use, Livestock and browse animals, Climate change, Invasive species and illegal trafficking of the genetic resource [2]. Plant illegal genetic resource trafficking is the movement export and import of plants and/or their derivatives for various methods without legal permits. This practice is highly common in the propinquity of national parks, conservation sites and borders. 
Although plant genetic resource conservation laws and regulations provide a variety of enforcement mechanisms to control the illicit plant genetic resource trade, implement mechanisms pose a huge challenge. Inadequate financial, human resources and lack of institutional capacity are barriers to enforcing these plant genetic resource laws [4].

There are several stakeholders (institutions, researchers, policy makers and public) working on biodiversity conservation and sustainable utilization. More over, further strengthening of coordination of the stakeholders are required for the effective conservation and sustainable utilization of biodiversity and ecosystems [2]. Therefore, this study was needed to survey the type, amount, route of plant genetic resource trafficking and develop stakeholder based control and benefit sharing for illegal plant genetic resource trafficking through Ethio-Sudan border, inthe northern part of Ethiopia.

\section{Material and Methods}

\subsection{Description of the Study Area}

The study was conducted in kafta Humera wereda, Tigray regional states of Ethiopia, which, bordered by Sudan and Eritrea externally as indicated in

Figure 1 below. kafta Humera wereda surrounds Setit Humera, capital city of Western Tigray Zone, kafta Humera and Setit Humera Weredas, in all sides. People in the study area lead their life by a mixed farming system (animal husbandry and crop farming).

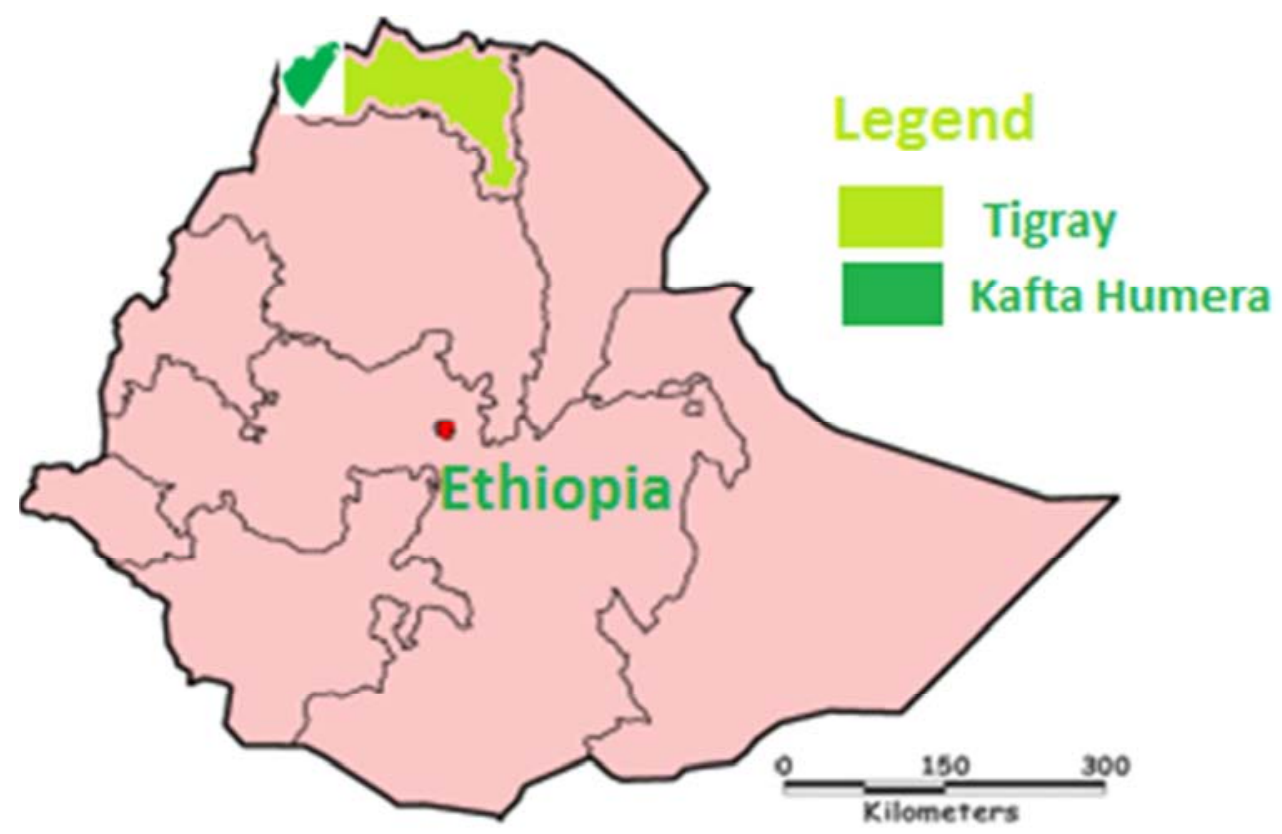

Figure 1. Map of Ethiopia indicating the study site.

\subsection{Research Design and Methodology}

A field survey was conducted from February to March 2017 in the selected border of Kafta Humera wereda, Tigray Regional States, Ethiopia. Data were collected on the status, route, ways of illegal trafficking and suggested management options of banned movement of plant genetic resources from concern offices based on the information obtain from the corresponding sector the wereda Administration. Accordingly, government sectors from the selected district offices were purposively selected based on their proximity to the issues under study. A total of 71 informants from various sectors were selected using a snowball sampling method [5] and purposive sampling methods based on their professional background and position towards the matter. These sectors include custom and revenue officers, local security, community resident and federal police officers.

The number of respondents was determined based on their availability number they were and consideration of budget and time. All informants were subjected to semi structured questioners design beforehand. In addition, semi-structured interview, focus group discussion and document analysis were used to exploit the remaining information on the illegal movement of plant genetic resources across the entire study wereda. Data was analyzed using SPSS software package version 20 to obtain simple descriptive statistics like frequency and percentage. More ever, Microsoft excel software was used to sketch charts such as bar graph and pie charts.

\section{Result}

\subsection{Background Information on Informants}

The number and type of informant included to participate in this research was depending on the real situation of the area under study. Accordingly, 30\% from custom and federal police officers, $42 \%$ from local security and $28 \%$ were from local community members (table 1). Besides, $47 \%$ of them were primary school completes (1-8) and 97\% of the respondents were male. Most of the participant was in the average age interval of above forty. 
Table 1. Informants profile and their site.

\begin{tabular}{|c|c|c|c|c|c|c|c|c|c|c|c|c|}
\hline \multirow[t]{2}{*}{ Sites } & \multicolumn{3}{|c|}{ No of sample taken } & \multicolumn{3}{|c|}{ Age interval } & \multicolumn{2}{|c|}{ Gender } & \multicolumn{4}{|c|}{ Educational level } \\
\hline & $\begin{array}{l}\text { Custom } \\
\text { \&Federal polices }\end{array}$ & $\begin{array}{l}\text { Local } \\
\text { Security }\end{array}$ & $\begin{array}{l}\text { Local } \\
\text { community }\end{array}$ & 20-30 & $31-40$ & $>40$ & M & $\mathbf{F}$ & Illiterate & $\begin{array}{l}\text { Primary } \\
(1-8)\end{array}$ & $\begin{array}{l}\text { Secondary } \\
(9-12)\end{array}$ & Tertiary \\
\hline Bereket & - & 11 & 6 & - & 2 & 15 & 17 & - & 4 & 13 & - & - \\
\hline Dima & 9 & 8 & 14 & 12 & 11 & 8 & 29 & 2 & 2 & 11 & 15 & 3 \\
\hline Lugdi & 12 & 11 & - & 8 & 8 & 7 & 23 & - & 3 & 9 & 8 & 3 \\
\hline Total & 21 & 30 & 20 & 20 & 21 & 30 & 69 & 2 & 9 & 33 & 23 & 6 \\
\hline
\end{tabular}

\subsection{Parts of Plant Trafficked from Ethiopia}

The result of the study reveals that $38 \%$ of most frequently trafficked plant parts were fruit, $31 \%$ stem, $15 \%$ root and $8 \%$ both gum and leaf parts (figure 2).

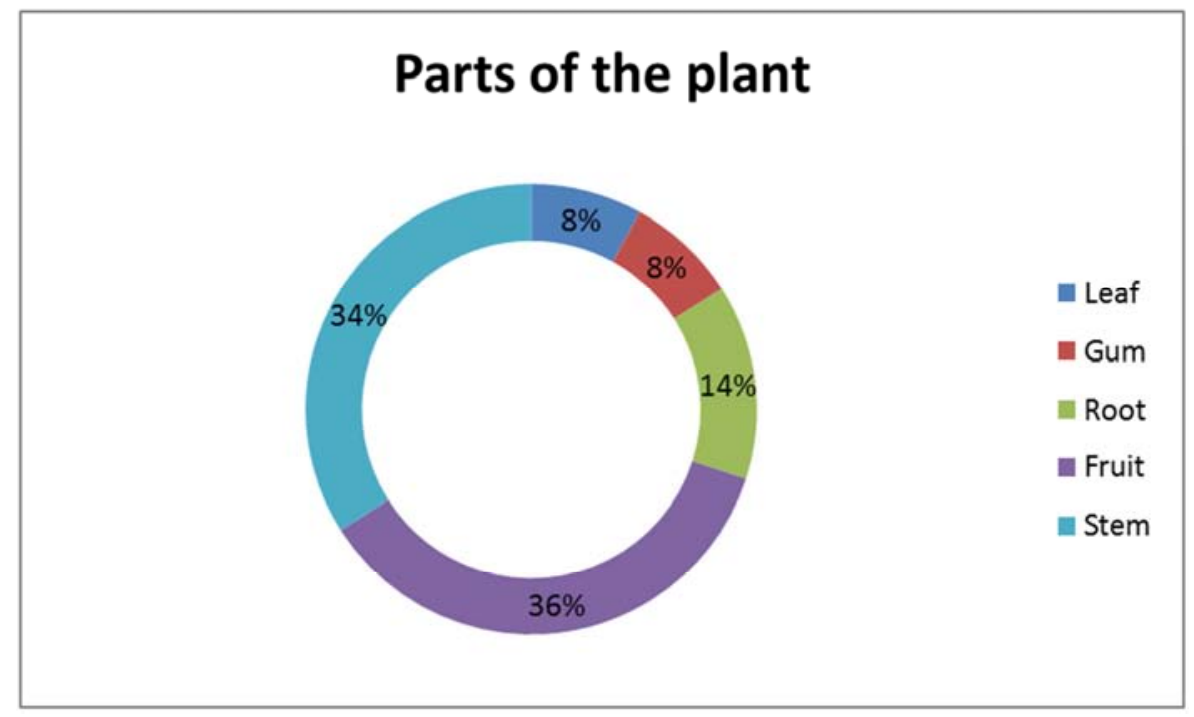

Figure 2. Parts of a plant trafficked from Ethiopia in percent.

\subsection{Type of Plant and Their Derivatives Trafficking}

The type of plant and plant derivatives most frequently trafficking through Ethio-Sudan border to Sudan were Rhamnus prinoides, Adansonia didgitata. Rhamnus prinoides trafficked its leaves and fruits together for the purpose of local drink or beverage ingredient in Eritrea. The remaining illegally trafficking plant and plant derivatives are used for medicinal, fumigation and food (Table 2).

Table 2. Type of plant and plant derivatives trafficking through the Ethio-Sudan border.

\begin{tabular}{llllll}
\hline No & Botanical name & Local name & Parts used & Use value & Smuggled to country \\
\hline 1 & Dalbergia melanoxylon & Zibe & Stem & Houseconstruction, factory product & Sudan \\
2 & Anogeissusleiocarpa & Hanse & Stem & House construction & Sudan \\
3 & Rhamnus prinoides & Gesho & Fruit, leave & Local beverage & Eritrea \\
4 & Boswelia paperifera & Etan & Gum & Fragrance & Sudan \\
5 & Adansonia didgitata & Dima & Fruit & For food & Sudan \\
6 & Balanites aegyptiacus & Mekie & Fruit & Produce oil food & Sudan \\
7 & Securidaca longepedunculata & Shitora & Stem & Medicinal & Sudan \\
8 & Acacia seyal & Tsaedachea & Root & Fumigation/tush & Medicinal \\
9 & Plumbago zeylanica & Aftuh & Root & Fragrance & Sudan \\
10 & Terminalia brownie & Weiba & Stem & oil product, Food \\
11 & Ziziphus spina-christi & Gaba & Fruit & Food \\
12 & Tamarindus indica & Humer & Fruit & & Sudan \\
\hline
\end{tabular}

\subsection{Awareness of Participants on Illegally Plant Resource Trafficking}

Based on the opinion of the informants the responsible actors for controlling illegal movement of plant genetic resources were community, administrative body, security force, and custom and revenue department.

\subsubsection{Community}

In the entire interviewed residents in the study area near to the checkpoint, there were community members that know illegal biogenetic resource trafficking in general. However, 
they were not committed to control it despite of their familiarity with it. Moreover, the illegal traffickers were living together with the community doing so without any challenge from the society. The highest frequency of the local community's gap on controlling illegal biogenetic resource trafficking is due to lack of prior knowledge of access permit as statistically proofed in the frequency table 3 below. This includes, they lack what to access and who can give a permission to smuggle plant resource.

Table 3. Awareness of the local community on genetic resource access permit?

\begin{tabular}{|c|c|c|c|c|c|c|}
\hline Sites & Descri & & Frequency & Percent & Valid percent & Cumulative percent \\
\hline \multirow{2}{*}{ Lugudi } & \multirow{2}{*}{ Valid } & Had prior Knowledge on access permit & 4 & 36.4 & 36.4 & 36.4 \\
\hline & & Noprior Knowledge on access permit & 7 & 63.6 & 63.6 & 100.0 \\
\hline \multirow{2}{*}{ Dima } & \multirow{2}{*}{ Valid } & Had Prior knowledge of access permit & 1 & 7.1 & 7.1 & 7.1 \\
\hline & & No Prior knowledge of access permit & 13 & 92.9 & 92.9 & 100.0 \\
\hline \multirow{2}{*}{ Bereket } & \multirow{2}{*}{ Valid } & Had Prior knowledge of access permit & 3 & 50.0 & 50.0 & 50.0 \\
\hline & & No Prior knowledge of access permit & 3 & 50.0 & 50.0 & 100.0 \\
\hline
\end{tabular}

\subsubsection{Checkpoint}

A member of checkpoint staff in the study site performs all duties given from the Ethiopian government like other check point cites together with other stakeholders. They were also trying to control the illegal trafficking through regular checking. Even though the community lacks commitment to control the illegal trafficking, members of check point (federal police) accomplish all activates by them. This could lack consistency in addressing the proclamation of concerning illegal plant genetic resource trafficking despite of their commitment.

\subsubsection{Revenue and Customs Authority}

The custom checkpoint administration addresses the illicit plant genetic resource trade through regular checks by assigning from the members of the federal police.

Members of the revenue and custom authority officers were also always in place to make their entire mandate required from them. Regarding the illegal trafficking they made a patrol method of checkouts

\subsubsection{Local Security}

The members of the local security surprisingly administer and enforce the law despite the fact that their membership of the society members. They establish a check point cite when the time and condition needs to do so. Their method of controlling was very admirable in enhancing the activities. However, they have many difficulties that should solve by society, governmental body and other stakeholders.

The main factor in the least implementation of illegal plant genetic resource were not a single issue that causes, rather it was the cumulative effect of low enforcement, least knowledge on legal framework, lack of training on proclamation and CITES and so on. Regarding the law enforcement practice, $72 \%$ of the interviewed informant confirms, it was not sufficient enough to cope the existing problem while $28 \%$ of them said it is sufficient enough. Besides, the highest number of informants didn't know the existence of the illegal local hidden market that illegal traffickers export through it. Informants in the study area didn't have prior knowledge on proclamation of plant genetic resource trafficking. In addition to that, they didn't take any training on conservation of endangered and threatened species (figure 3 )

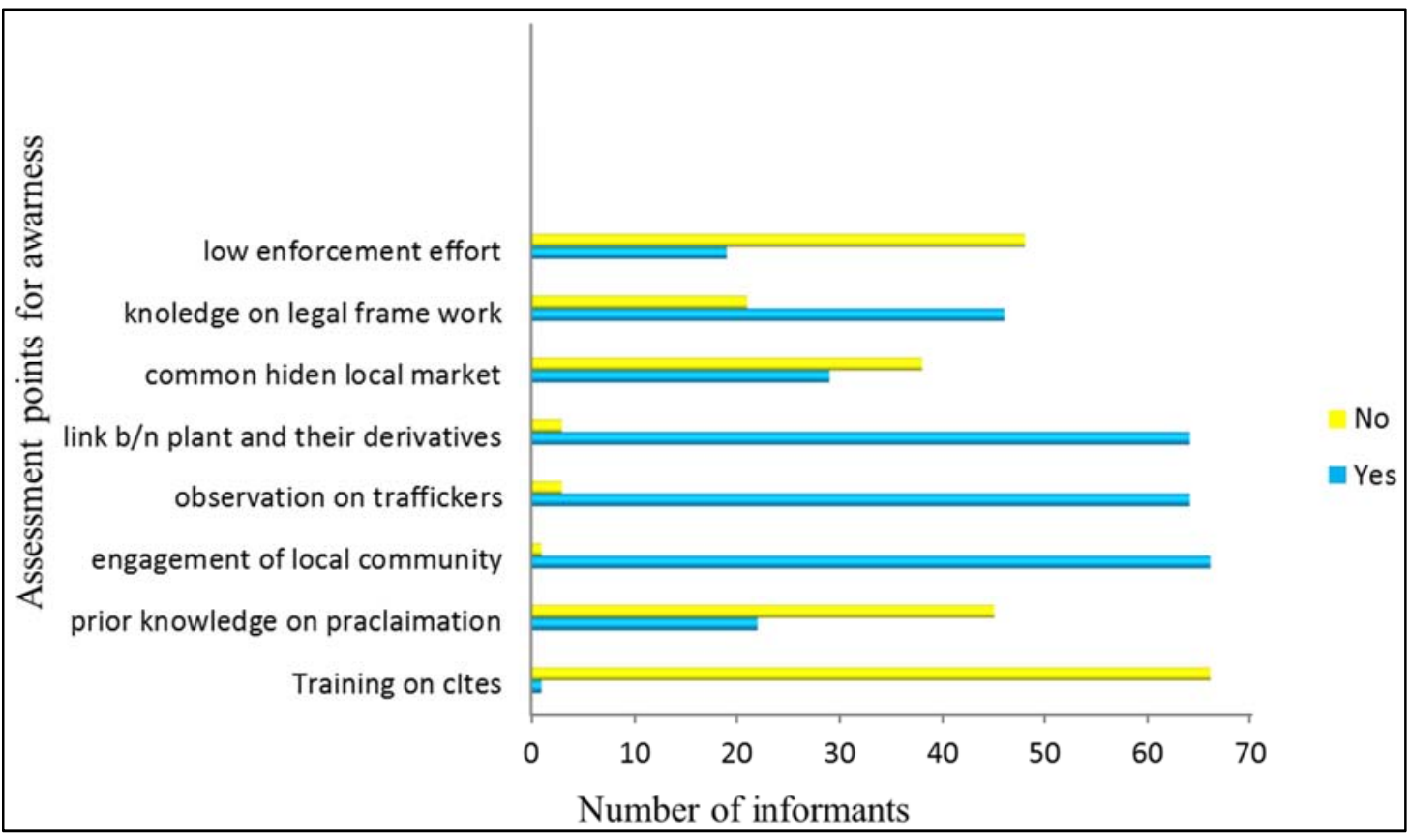

Figure 3. Assessment of informants' awareness on plant resource trafficking. 


\subsection{Smugglers of Illegal Plant Genetic Resource Trafficking and Access}

The Community members that involved in illegal plant genetic resources trafficking were Farmers, unemployed youths, local brokers even the citizens in the neighboring states.

Unemployed youth:

The number of unemployed youth in check point near area and surroundings were very huge. These unemployed youth had, not only from the surrounding areas, but also from various localities of Ethiopia. The reason why they come to this area was not well known. However, most probably the local communities' deduce they were coming for the purpose of illegal trafficking of biogenetic resource and other goods. The existence of such a large number of unemployed youth had a devastating effect for illegal biogenetic resource trafficking. The local security and member of the Dima check point confirms what the local communities had said. Besides, the researcher's observation on the illegal exit point found true. They were all youths which didn't have another alternative job to lead their life.

Farmers; the community in the boarder sides of kaftahumera and surrounding area lead their life by mixed farming system (crop farming and animal husbandry). There were also communities that lead their life by selling and buying common goods in a small scale. Concerning the illegal biogenetic resource, particularly the plant role, there were farmers that act as co- traffickers, direct ways and seasons for doing trafficking activities as the local security and check point member informed during the interview. The illegal traffickers cooperate with farmers in order to smuggle themselves from security bodies. Therefore, the farmers in the study sites were not in a required position to struggle the illegal biogenetic resource that carried out in their surrounding area.

Investors; There were different types of investors in the boarder of the study wereda. To list some of them; cereal farming investors, animal fattening investors, importers and exporters of goods. These investors were not all absolute in struggling the illegal plant genetic resource. There were investors that exports unpermitted goods, biological resources together with the legal one by cheating the legal routes. This was from the experience of local security and other legal concerned bodies and the researcher observation. Therefore biogenetic resource trafficking were not that much a single line that perform by a single person, group or community rather it was a complex Phenomena remain difficult to control completely in the study area.

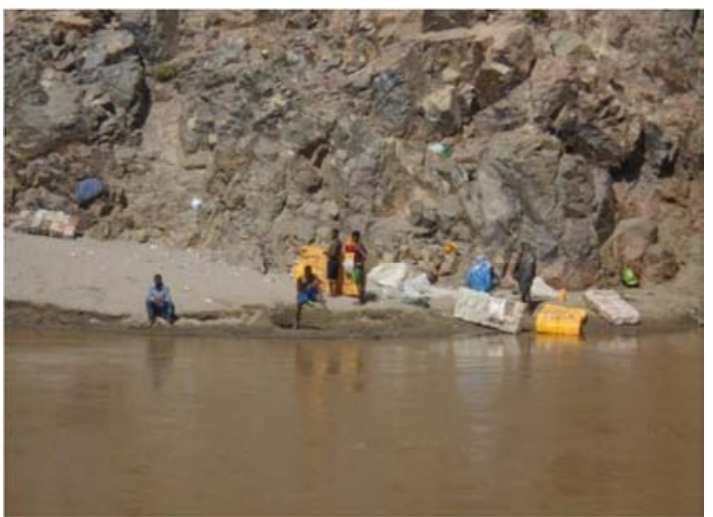

Figure 4. Illegal traffickers withtheir traditional boat on Eritrea and Sudan side.

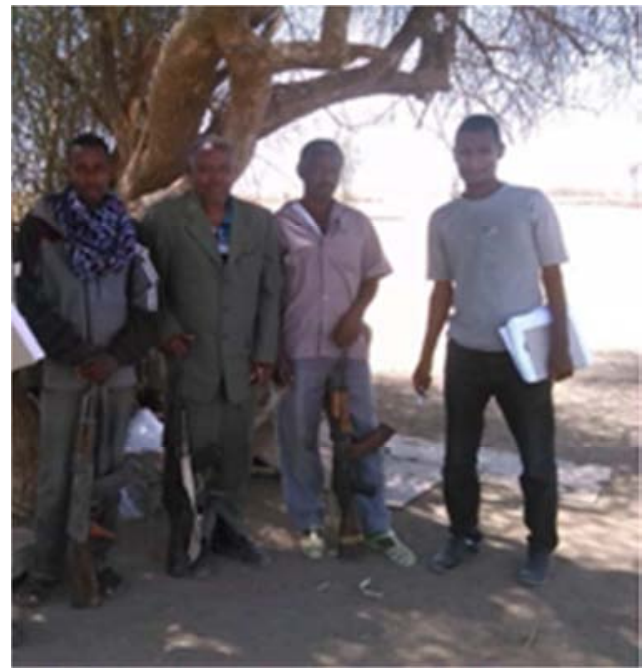

Figure 5. The local security on their checkpoint site near humera. 


\subsection{Entry and Exit Point of Illegal Biogenetic Resource Trafficking}

There were about 22 routes listed with their Gps coordination by which biogenetic resources were trafficked to another country from Ethiopia both legally and illegally (Table 4). These routes are reduced to the nearest three main checkpoint routes for reporting purposes in Table 1 above. Those were Dima, Bereket and Lugudi check points. The main illegal route whereby most illegal traffickers use to export plant and plant derivative were Maytselot, Menkerker, Awezruf, endaaboy Tewelde jerdin and haji abdu jerdin.

Table 4. GPS Points in Kafta Humera Wereda Exit Rout Genetic Resource/GR Trafficking.

\begin{tabular}{|c|c|c|c|c|c|c|}
\hline \multirow{2}{*}{$\mathbf{S} / \mathbf{N}$} & \multicolumn{2}{|c|}{ Gps coordination } & \multirow{2}{*}{ Altitude } & \multirow{2}{*}{ Tabia } & \multirow{2}{*}{ Specific Place } & \multirow{2}{*}{ Type of biogenetic resource exported } \\
\hline & Easting & Northing & & & & \\
\hline 1 & 0237143 & 1578942 & 556 & Rawyan & Abyi menqerqer & Teff \\
\hline 2 & 0237268 & 1579277 & 564 & Rawyan & Meragefi at Abyi menqerqer & Station of Traffickers where they exchange GR \\
\hline 4 & 0236823 & 1577387 & 544 & Rawyan & Zban mdmar Tekeze-rawyan & Tekeze \& Rawyan rivers combined \\
\hline 5 & 0236757 & 1577643 & 557 & Rawyan & Shwshwit & Traffickers pass to Sudan-Eritrea border \\
\hline 6 & 0236271 & 1577125 & 559 & Rawyan & Azruf & $\begin{array}{l}\text { Adansonia didgitata, animals, crops, Rhamnus prinoides } \\
\text { and drugs pass to Hamdait (Sudan) }\end{array}$ \\
\hline 7 & 0237217 & 1557215 & 666 & Mycadra & Mycadra town & passageway and destination of Traffickers \\
\hline 8 & 0216976 & 1547724 & 627 & Mycadra & Lgudi Check point & $\begin{array}{l}\text { people and materials are passed legally through Road } \\
\text { transport }\end{array}$ \\
\hline 9 & 0233859 & 1538046 & 675 & Mycadra & $\begin{array}{l}\text { Enda Shumye Gebru Cotton } \\
\text { farm }\end{array}$ & $\begin{array}{l}\text { Traffickers pass through it to Mechach \& bahreselam then } \\
\text { to sudan }\end{array}$ \\
\hline 10 & 0230795 & 1523666 & 641 & Mycadra & near enda weyane cambo no 1 & $\begin{array}{l}\text { Banat, Traffickers pass through it to Mechach \& } \\
\text { bahreselam then to sudan }\end{array}$ \\
\hline 11 & 0224537 & 1524546 & 548 & Mycadra & Bahreselam river & $\begin{array}{l}\text { An Exit route to Abderafie then to Sudan, where taf, } \\
\text { animals and Dalbergia melanoxylonare trafficked }\end{array}$ \\
\hline 12 & 0216883 & 1532022 & 604 & Mycadra & Enda Guesh/Afera cambo & $\begin{array}{l}\text { An Exit route in land to Sudan, near to Awetir of Amhara- } \\
\text { sudan border }\end{array}$ \\
\hline 13 & 0210433 & 1533783 & 579 & Mycadra & A forestat Mechach & animals, Teff, Dalbergia melanoxylon \\
\hline 14 & 0210746 & 1536756 & 609 & Mycadra & Enda Tsegay Grmay cambo & animals and crops \\
\hline 15 & 0211162 & 1539793 & 595 & Mycadra & Near Beshr Cambo & animals, crops, charcoal and construction woods \\
\hline 16 & 0216025 & 1533687 & 629 & Mycadra & $\begin{array}{l}\text { Last point for the Lgudi area to } \\
\text { Redem }\end{array}$ & An Exit route for Genetic Resources and other materials \\
\hline 17 & 0238271 & 1545948 & 678 & Mycadra & Bewal area & $\begin{array}{l}\text { traffickers from maycadra, Sheglil, Baeker and Lugudi } \\
\text { passed through it, to Border areas }\end{array}$ \\
\hline 18 & 0223422 & 1549872 & 684 & Mycadra & Jemam & $\begin{array}{l}\text { Kunama ethnic, known to utilize wild forest fruit like } \\
\text { Adansonia didgitata, Tamarindus indicaetc }\end{array}$ \\
\hline 19 & 0227325 & 1565985 & 598 & Bereket & Bereket town & A town where Center of traffickers \\
\hline 20 & 0224182 & 1575113 & 596 & Bereket & endabo haji & Common Exit route for Teff and goods \\
\hline 21 & 0218647 & 1575172 & 571 & Bereket & Endagaba exite route & Common Exit route for animals \\
\hline 22 & 0224619 & 1574705 & 542 & Bereket & Endaboy Tewelde & animals, Teff, coffee and vegetables $\&$ fruits \\
\hline
\end{tabular}

\section{Discussion}

The way of trafficking Rhamnus prinoides from Ethiopia to Eritrea was by using Sudan border and then redirect to Eritrea before it enters to the mainland of Sudan through illegal traffickers of both Eritrea and Sudan. Regarding Adansonia didgitata, its fresh fruit were trafficked for the purpose of domestic consumption because of edible nature it has. According to [6] various parts of Adansoniadigitata (leaves bark and seeds) were used as a panacea, that is, used to treat almost any disease. Dalbergia melanoxylon (African black wood) was the type of plant in the western and northwestern zone of Tigray which highly threatens by domestic user and illegal traffickers. It was illegally trafficked for factory product and construction purpose due to its hard stem part in nature. In Tanzania increasing harvesting of Dalbergia melanoxylon for commercial timber, forest clearing for new settlements and agriculture, frequently occurring bushfires, low regenerative ability of the species by natural methods and lack of the national conservation efforts presents a serious threat to the future availability [7].

The root of Acacia seyal was trafficked for the purpose of fumigation. Married female in Sudan mostly (50\%) uses Acacia seyal for Dokhan (smoke) [8]. Dokhan is a traditional Sudanese smoke in which woman wraps her entire body in a blanket and sits on a hole in the ground. The use of root part for fumigation and other purpose cause the plant in a severe threat. Ethiopia had no legal export and import of products for medicinal use but plants of medicinal importance were exported to Djibouti and other countries as agricultural products [9].

The 1997 IUCN Red Listgives threatened Plants by International trade in Kenya through smuggling and this might soon pose a threat to Ethiopia if appropriate control methods and propagation are not timely put in place [10].

Based on this result, the highest plant part from the most 
frequently trafficked from Ethiopia was the fruit part. This could have lost of the patent use on biodiversity resource in the case of endemic, indigenous and rare plants in Ethiopia [11]. Besides, the use of more leaf part repeatedly causes deforestation on the plant genetic resource. The high treat to the destruction of mother plant move toward with root, bark and leafy - stem harvest [12], [13], [14], [15].

The major plant and plant derivatives resource illegally imported to Ethiopia was not that much bulk as compared to the illegally exported. Only one type of plant was repeatedly entered by trans boundary travelers through the Lugudi check point for the purpose of shading. The local people call it "Sundance's tree". Morphologically, it had rapid growth and better quality of the canopy for shading in the dry season of the area. However, there was a considerable amount of goods trafficked from Sudan to Ethiopia through the illegal entry places adjacent to the three checkpoint areas. These include powdered detergents, clothes, electronics (such as television, radio, dish, and receiver), shoes, belts and watches. Illegal traffickers collect a plant resources from a cultivated area, protected area and national parks particularly from the nearby national park, kafta sheraro.

Illegal trafficking in plants, their parts and derivatives were a worldwide phenomenon that has severe implications for biodiversity, ecosystems and national economies. It also threatens sustainable conservation of biodiversity which is driving many species towards extinction [16]. Much of this trade is from developing countries, which contain most of the world's biodiversity, to developed ones, which supply the demand. The trade is demand driven targeting rare, protected and highly endangered species of wildlife and is driving many species to the threshold of extinction. This demand and price for wildlife products in the illegitimate market persists to drive poaching. Most knock species on commercial scale, indigenous tree species for timber and charcoal. This leads to environmental degradation with adverse effects such as climate change, global warming and water scarcity.

In an effort to combat these conservation challenges and enhance plant security, the Government of Ethiopia through the Ethiopian biodiversity institute (EBI) and other agencies has taken various policy, legislative and operational measures. EBI is actively collaborating with the local communities neighboring the National Parks and Reserves and has also been working closely with other law enforcement agencies within Ethiopia, regionally and internationally to ensure that the illegal trafficking of wildlife species and their products is curbed by recruiting professional experts at the exit routes.

\section{Conclusion}

Assessment of these illegally trafficked plants resource are essential from the perspective of conservation and sustainable use of plants, which consequently helps in formulation of potential raw materials in modern industry of pharmaceutical and other ornamental use values for further availability and utilization of humanbeing.
In Kafta humera, unemployed youth and people with low daily income of the local community collect plants from the different sources and then trafficked in order to complement their daily incomes. Due to unemployment and lack of knowledge of proclamation increasing market demand, numerous plant species were threatened with extinction. For rational and regulated collection and use, local community control measures are necessary. It is also essential to promote the cultivation of these plants frequently trafficked plants that would provide strong implicate for conservation. The existing gap in community responsiveness needs awareness raising and alternative job opportunity creations of the unemployed community members.

\section{Acknowledgements}

The author is thankful to the local security, community and crosponding government sectors of Kafta humera wereda for their kind response during the study and to Semere Tsewene for his assistance during data collection and entry. The Ethiopian biodiversity institute Mekelle biodiversity center for the fund and director ofMekelle biodiversity center, Dr. Mebrahtom mesfin, is thankful for his support and follow up.

\section{References}

[1] FAO (food and Agriculture Organization) The State Of the World's Forest Genetic resources Commission on Genetic Resources for Food and Agriculture. Food and Agriculture Organization of the United Nations, Rome, Italy (2014).

[2] NBSAP (2015). National Biodiversity Strategy and Action Plan of Ethiopia. Ethiopia Biodiversity Institute, Addis Ababa, Ethiopia.

[3] CBD (1992). Convention on Biological Diversity. Secretariat of the convention on biological diversity: United Nations Environment Program. Montreal. Canada.

[4] Kaaria D and Muchiri M. (2011). Ninth International Conference on Environmental Compliance and Enforcement. Pp 204-208.

[5] Patton, M. (1990) Qualitative evaluation and research methods, sage Publications, Newbury Park, California. Pp. 169-186.

[6] G. P. P. Kamatou, I. Vermaak, A. M. Viljoen An updated review of Adansonia digitata: A commercially important African tree South African Journal of Botany 77(2011)908919 Available online at www.sciencedirect.com

[7] Washa B. Washa 2014 A Review of the Literature of Dalbergia melanoxylon International Journal of Plant and Forestry Sciences Vol. 1, No. 1, PP: 1-6 Available online http://www.ijpfs.com/

[8] Abdalbasit Adam, Noha Mohammed Fadl, Fatima Omer, Alfatih Ahmed. Ethno botanical study of three trees: indigenous knowledge on trees used as cosmetic in Khartoum state, Sudan Asian Journal of Pharmaceutical Science \& Technology Vol 4 (4) 2014, pp 178-182.

[9] Marshall, N. T. 1998. Searching for a cure, Conservation of medicinal wildlife resources in East and Southern Africa. TRAFFIV network report. 
[10] Endashaw Bekele. 2007. Study on actualsituation of medicinal plants of Ethiopia. Http//www:endashaw.com.

[11] Edeget Merawi, Ashenafi Ayenew, Fikremariam Ghion. Surveying Illegal Access to Genetic Resources: A Case Study in Borena Zone, Southern, Ethiopia. International Journal of Natural Resource Ecology and Management. Vol. 1, No. 4, 2016, pp. 162-170. doi: 10.11648/j.ijnrem.20160104.13.

[12] Mirutse G; Zemede A; Elmquist T; Zerihun W. (2003). An ethnobotanicalstudy of medicinal plants used by the Zay people in Ethiopia. J. Ethno pharmacology, 85 (1): 43-52.

[13] Haile Y; Delensaw Y. (2007). Traditional medicinal plant knowledge and use bylocal healers in Sekoru District, Jimma Zone, South western Ethiopia. J. Ethnobiol. And Ethnomed, 3: 3-24.
[14] Balcha A. Medicinal plants used in traditional medicine by Oromo people, Ghimbi District, South Western Ethiopia. Journal of Ethnobiology and Ethnomedicine, 2014, 10: 4050 .

[15] Fitsumbirhan Tewelde. Marketable Medicinal, Edible and Spice Plants in Endasilase-Shire District Tigray Regional State, Ethiopia Article in Press:-http://sciencedomain. org/journal/46/articles press

[16] Getachew Mulualem, Weldemariam Tesfahunegny. Contemporary Status of Illicit Wildlife Genetic Resource Trafficking: Future Policy, Legal and Institutional Consideration of Sustainable Wildlife Conservation in Ethiopia, Journal of Zoology Studies 2016; 3(4): 91-10. 